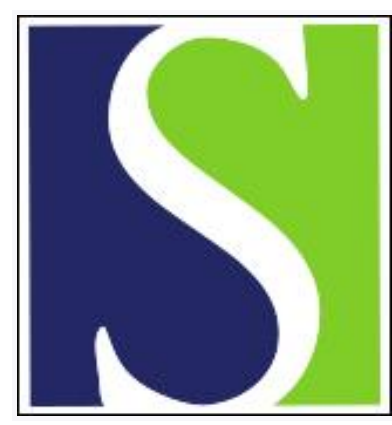

Scand J Work Environ Health 1998;24(4):262-269

https://doi.org/10.5271/sjweh.319

Issue date: Aug 1998

\title{
Determinants of asthma in a farming population
}

by Melbostad E, Wijnand E, Magnus $P$

The following article refers to this text: 2002;28(1):49-57

Key terms: airway obstruction; asthma; cross-sectional study; family history; farmer; genetic factor; occupational exposure; smoking

This article in PubMed: www.ncbi.nlm.nih.gov/pubmed/9754857

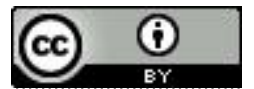




\title{
Determinants of asthma in a farming population
}

\author{
by Erik Melbostad, MD, ${ }^{1}$ Wijnand Eduard, PhD, ${ }^{1}$ Per Magnus, MD'
}

\author{
Melbostad E, Wijnand E, Magnus P. Determinants of asthma in a farming population. Scand $J$ Work Environ \\ Health 1998;24(4):262-269.
}

\begin{abstract}
Objectives This study examined the determinants of asthma in a population of farmers, including as a crude indicator of genetic predisposition "history of asthma in next-of-kin" (family history), and exposure factors such as animal production and smoking.

Methods In a cross-sectional study of 8482 farmers or farmers' spouses in Norway a questionnaire with information on asthma among the subjects and their next-of-kin, production type and farming activities, exposures outside farming, and smoking was applied. Spirometry was performed.

Results The lifetime prevalence of self-reported asthma in the population was $6.3 \%$. Significant risk factors for current asthma were asthma among next-of-kin, asthma as child or adolescent, animal production, and age. In a comparison with subjects with no family history of asthma and no animal production the adjusted odds ratio for current asthma in never smokers was 1.9 [95\% confidence interval $(95 \% \mathrm{Cl}) 0.4-8.9]$ for subjects with family history only, $2.2(95 \% \mathrm{CI} 1.1-4.2)$ for subjects with animal production only, and 6.3 (95\% CI 3.1-13.1) for subjects with both factors. A combination of animal production, smoking, and a positive family history gave an odds ratio of 8.1 (95\% CI 4.0-16.2) for current asthma.

Conclusions The study can be interpreted as support for the hypothesis of an interaction between genetic factors and exposure factors in the causation of asthma. Since familial associations may be exposure-related, the necessity of considering indicators of both inheritance and exposure in epidemiologic studies of asthma is emphasized.
\end{abstract}

Key words asthma, airway obstruction, cross-sectional study, family history, farmers, genetic factors, occupational exposure, smoking.

Increasing prevalences of asthma have been reported in the industrialized world $(1,2)$. The causes of asthma are largely unknown (2). It is hypothesized that genetic factors interact with environmental exposure to produce asthma (3). However, the relative importance of genetic and exposure factors in the causation of asthma are not known, partly because of a lack of relevant indicators of heredity.

Immunologically potent substances such as antigens, allergens, endotoxins, glucans, and substances with complement-stimulating and adjuvant effects have been identified in agricultural dust of different origins (4-6). The inhalation of agricultural dust provokes inflammatory reactions in the airways $(5,7)$. Among farmers in the Nordic countries exposure in animal production (dairy, swine, poultry) is daily and indoors the whole year. For farmers without animal production, the dust exposure is limited to short seasons (eg, crop production like grain).
Population studies of respiratory health among farmers have focused on chronic bronchitis and different airway symptoms, airway obstruction, and bronchial reactivity $(8-11)$. There have been few studies on the occurrence of asthma in population studies of farmers $(8$, 12 ), and no studies on the interaction between genetic predisposition and exposure.

Self-reporting of asthma by questionnaire has been shown to be a simple, reliable, and specific method for identifying asthma in populations $(1,13-16)$. As there is a need for robust indicators of genetic predisposition in epidemiology, we have used "history of asthma in next-of-kin" as a crude indicator of genetic predisposition. Our aim was to study the effects of exposure factors such as animal production and smoking, and also genetic predisposition and the joint effects of these factors as determinants of asthma in a population of farmers.

Reprint requests to: Dr Erik Melbostad, National Institute of Occupational Health, PO Box 8149 - Dep, 0033 Oslo, Norway. [e-mail: Erik.Melbostad@stami.no] 


\section{Subjects and methods}

\section{Subjects}

Norway has about 100000 small family farms, with stable ownership over several generations. As a part of a system for economic support to farmers, the Norwegian government annually registers information on the farmers and their production. On the basis of the file for 1989 and the Central Bureau of Statistics' marriage register, a cohort of farmers and spouses was defined. The inclusion criteria were farmers with at least 0.4 person-years of farming and spouses with more than 500 hours of farm work in 1989, and those who had retired in 1986-1989 at ages between 20 and 67 years (69 years in 1991).

Altogether 41 municipalities were randomly selected from 3 counties of southern Norway. All of the 10792 eligible farmers and spouses in these municipalities were invited to participate in a cross-sectional study during the winter of 1991, and 8482 persons (78.6\%) who attended a personal examination were included in the study. There were only slight differences in the arable land and other characteristics of the farm between the nonrespondents and respondents. Both farmers and spouses with animal production had an average of 5 hours longer farm work per week than persons without animal production. Exposure in dusty occupations outside farming during the subjects' careers were reported by 1968 persons (table 1).

\section{Asthma}

The participants received a letter of invitation and selfadministered questionnaires containing questions on asthma in childhood and adolescence, asthma in adulthood, beginning of asthma symptoms in the last 10 years, current asthma (asthma now), and physician's diagnosis of asthma, as well as asthma among next-of-kin (parents and siblings), spouse, and offspring. (See tables 2 and 3.) The questions on "asthma ever" and "asthma diagnosed by a physician" had been earlier applied in Norwegian and Swedish population studies $(14,17,18)$.

\section{Indicators of exposure, selection and heredity}

The selected exposure variables were animal production (all kinds of animal husbandry except domestic pets) versus no animal production and workhours per week on the farm (part-time versus full-time farming). The factors used to indicate selection were "production change because of dust nuisance" and "retirement". Smoking was categorized as never smokers (never daily smoking) and ever smokers (current daily smokers and ex-smokers) to avoid the healthy smoker effect that is sometimes observed when "current smoking" is applied as the smoking category. The indicator used for genetic predisposition was "history of asthma among next-of-kin" (parents or siblings) as reported on the questionnaire (abridged as "family history").

\section{Spirometry}

Spirometry was performed in the sitting position with 4 Vitalograph $\mathrm{S}$ (volumetric) spirometers operated by trained personnel with a protocol according to the recommendations of the American Thoracic Society (19). Room and spirometer temperature, as well as barometric pressure, was recorded. Each subject performed at least 3 preferably identical forced vital capacity curves (ie, within a variation of $50 \mathrm{ml}$ or a maximum of $2 \%$ ). The best of the forced expiratory volume in 1 second $\left(\mathrm{FEV}_{1.0}\right)$ values, corrected for pressure and temperature (BTPS, body temperature, pressure, saturated) (20), were selected for statistical analysis. Fifty-five persons did not complete the spirometric examination.

\section{Statistical methods}

The reliability of the responses to the asthma questions was studied for 280 persons in 1 municipality in 1990 and 1991. The agreement between the responses was estimated as the percentage consistency (16) and the prevalence-adjusted consistency (Cohen's kappa) $(16,21)$.

The prevalences of the symptoms in relation to the exposure categories were analyzed by cross-tabulation assisted by logistic regression according to principles described by Rothman (22) and Hosmer \& Lemeshow (23). Risk factors were introduced into the models one by one and by combinations to study possible confounding and interaction. The interactions were evaluated according to principles described by Rothman (22) and Hallqvist et al (24). Relative excess risk was calculated according to additive interaction models as indicated by Rothman:

$$
R E R I=O R(A B)-O R(A \underline{B})-O R(\underline{A B})+1,
$$

where $A=\operatorname{exposure} A, \underline{A}=$ not exposure $A ; B=$ exposure $B, \underline{B}=$ not exposure $B$.

Lung function (FEV ${ }_{1.0}$ as the dependent variable) was analyzed with linear regression for height and age separately for the men, women, never smokers, and ever

Table 1. Age, years in agriculture, farm work hours per week, work exposure outside agriculture, and smoking habits of the study population ( $\mathrm{N}=8482)$.

\begin{tabular}{lccc}
\hline Characteristic & Mean & SD & $\%$ \\
\hline Age & 49.3 & 10.8 &. \\
Years in agriculture & 25.2 & 13.7 &. \\
Farm work (hours per week) & 40.3 & 20.9 &. \\
Smoking & & & \\
$\quad$ Never smoked &. &. & 46.5 \\
Current smoker &. &. & 29.8 \\
$\quad$ Former smoker &. &. & 23.7 \\
Dust exposure outside farming &. &. & 23.2 \\
\hline
\end{tabular}


Table 2. One-year reliability of the asthma question responses, consistency, and kappa values for 1990 and 1991 ( $N=280)$. (SE = standard error)

\begin{tabular}{|c|c|c|c|c|c|c|c|}
\hline & \multicolumn{2}{|c|}{1990} & \multicolumn{2}{|c|}{1991} & \multirow{2}{*}{$\frac{\text { Consistency }}{\%}$} & \multirow[t]{2}{*}{ Kappa } & \multirow[t]{2}{*}{ SE } \\
\hline & $\mathrm{N}$ & $\%$ & $N$ & $\%$ & & & \\
\hline \multicolumn{8}{|l|}{ Asthma in family } \\
\hline Father, mother, brother, sister & 48 & 17.1 & 37 & 13.2 & 94.9 & 0.76 & 0.05 \\
\hline Children & 20 & 7.1 & 13 & 4.6 & 94.6 & 0.52 & 0.11 \\
\hline Spouse & 13 & 4.6 & 9 & 3.2 & 97.1 & 0.62 & 0.12 \\
\hline \multicolumn{8}{|l|}{ Asthma, self-reported } \\
\hline Ever & 28 & 10.0 & 25 & 8.9 & 95.4 & 0.74 & 0.07 \\
\hline In childhood or adolescence & 15 & 5.4 & 13 & 4.6 & 97.9 & 0.70 & 0.09 \\
\hline As adult & 18 & 6.4 & 11 & 3.9 & 94.6 & 0.46 & 0.12 \\
\hline Diagnosis by physician & 22 & 7.9 & 19 & 6.8 & 96.0 & 0.71 & 0.08 \\
\hline Cumulative asthma, all responses (not family) & 30 & 10.7 & 29 & 10.4 & 96.0 & 0.79 & 0.06 \\
\hline
\end{tabular}

Table 3. Prevalence of asthma response categories (self-reported asthma, $N=8482$ ).

\begin{tabular}{lrr}
\hline Nonexclusive categories & $\mathrm{N}$ & $\%$ \\
\hline Asthma in childhood or adolescence & 195 & 2.3 \\
Asthma as adult & 394 & 4.6 \\
Asthma now (currently) & 263 & 3.1 \\
Asthma started (first time) in last 10 years & 203 & 2.4 \\
Asthma diagnosis by physician & 347 & 4.1 \\
Asthma past or present, all responses cumulated & 531 & 6.3 \\
Current user of asthma medication & 221 & 2.6 \\
Asthma in family & & \\
$\quad$ Father, mother, brother, sister & 1064 & 12.5 \\
Children & 537 & 6.3 \\
Spouse & 268 & 3.2 \\
\hline
\end{tabular}

smokers. Never smoking men and women were selected as internal references for the calculations of predicted values, residuals, and standardized residuals.

The resulting internal reference equations were as previously published (25):

Women: $\mathrm{FEV}_{1.0}$ predicted $=3.956 \times$ height in meters $-0.023 \times$ age -2.500 (SD 0.555)

and

Men: $\mathrm{FEV}_{1.0}$ predicted $=4.615 \times$ height in meters $-0.027 \times$ age 3.106 (SD 0.648).

Residuals and standardized residuals were calculated for the $\mathrm{FEV}_{1.0}$.

\section{Results}

\section{Asthma}

The 1-year reliability of the asthma questions is presented in table 2 . The percentage of consistency varied from 95 to 98 , and the kappa values ranged from 0.46 to 0.79 . Asthma started in past 10 years and current asthma were not tested in 1990 .
The overall lifetime (cumulative) prevalence of asthma was $6.3 \%$ (table 3 ). The prevalence was $3.1 \%$ for current asthma, $2.6 \%$ for current use of medication for asth$\mathrm{ma}$, and $2.4 \%$ for asthma started in past 10 years.

\section{Standardized residuals for forced expiratory volume in one second}

The standardized residuals for $\mathrm{FEV}_{1.0}$ were analyzed for never smokers and ever smokers separately (table 4). There was a significant difference in the base-line mean value for the standardized residuals for nonasthmatic never smokers [mean $0.007,95 \%$ confidence interval $(95 \%$ CI) $-0.023-+0.036]$ versus ever smokers (mean $-0.181,95 \% \mathrm{CI}-0.212--0.149$ ). The asthma categories had significantly lower means for the standardized residuals for ever smokers than for never smokers, except for asthma diagnosed by a physician (table 4).

\section{Risk factors for asthma}

The associations between the asthma categories and the risk factors are shown in table 5 . The risk factors for current asthma were asthma among next-of-kin [adjusted odds ratio (OR) $2.9,95 \%$ CI 2.3-3.7), asthma in youth or adolescence (OR 22.2, 95\% CI 15.2-32.4), production change because of dust (OR $8.4,95 \%$ CI 4.5-14.3), livestock production (OR 1.6, 95\% CI 1.1-2.2), other dusty occupation (OR 1.2, 95\% CI 0.9-1.6), and smoking (OR 1.3, 95\% 1.0-1.7). The importance of age as presented in this report (table 5), or alternatively as years in agriculture, was significant. All the factors were included in the model for each outcome (table 5), and the removal of single factors did not influence the observed odds ratios substantially.

When never smokers were analyzed separately, the adjusted odds ratio for other dusty occupations was 1.82 (95\% CI 1.03-3.15) (same model as used in table 5).

To avoid possible effects of seasonal variation, the outcome "asthma in adulthood" was analyzed. It showed the same associations as current asthma. Likewise the indicator of late onset asthma or new cases, "asthma started in past 10 years", showed similar associations. 
Table 4. Standardized residuals of the forced expiratory volume in 1 second $\left(F E V_{1.0}\right)$ for the never smokers $(N=4050)$ and ever smokers $(\mathrm{N}=4377) .{ }^{\text {a }}(95 \% \mathrm{Cl}=95 \%$ confidence interval)

\begin{tabular}{|c|c|c|c|c|c|c|}
\hline \multirow[t]{2}{*}{ Asthma categories } & \multicolumn{3}{|c|}{ Never smokers } & \multicolumn{3}{|c|}{ Ever smokers } \\
\hline & N & $\begin{array}{l}\text { Standardized } \\
\text { residual (mean) }\end{array}$ & $95 \% \mathrm{Cl}$ & N & $\begin{array}{l}\text { Standardized } \\
\text { residual (mean) }\end{array}$ & $95 \% \mathrm{Cl}$ \\
\hline No self-reported asthma & 3809 & 0.007 & $-0.023-+0.036$ & 4045 & -0.181 & $-0.212--0.149$ \\
\hline Cumulative asthma & 241 & -0.389 & $-0.483--0.195$ & 332 & -0.749 & $-0.877--0.620$ \\
\hline Asthma diagnosed by physician & 134 & -0.530 & $-0.715--0.344$ & 209 & -0.846 & $-1.006--0.684$ \\
\hline Asthma as adult & 162 & -0.407 & $-0.588--0.224$ & 228 & -0.917 & $-1.067--0.765$ \\
\hline Asthma started in last 10 years & 83 & -0.235 & $-0.460--0.009$ & 117 & -0.985 & $-1.205--0.765$ \\
\hline Asthma now & 102 & -0.493 & $-0.731--0.255$ & 159 & -1.089 & $-1.279--0.896$ \\
\hline Current user of asthma medication & 94 & -0.659 & $-0.944--0.373$ & 124 & -1.271 & $-1.506--1.035$ \\
\hline
\end{tabular}

a The standardized residuals of the $\mathrm{FEV}_{1.0}$ were adjusted for age, height, and gender and standardized for standard deviation of the reference distribution, predicted mean $=0, S D=1$.

Table 5. Risk factors, prevalences, and odds ratios ${ }^{a}(\mathrm{OR})$ for asthma and airway obstruction $(\mathrm{N}=8482) .(95 \% \mathrm{Cl}=95 \%$ confidence interval)

\begin{tabular}{|c|c|c|c|c|c|c|c|c|c|c|}
\hline \multirow[t]{2}{*}{ Risk factors } & \multirow[t]{2}{*}{$\mathrm{N}$} & \multicolumn{3}{|c|}{ Asthma now } & \multicolumn{3}{|c|}{ Asthma as adult } & \multicolumn{3}{|c|}{$\begin{array}{l}\text { Asthma started } \\
\text { in last } 10 \text { years }\end{array}$} \\
\hline & & $\%$ & $O R^{a}$ & $95 \% \mathrm{Cl}$ & $\%$ & $O \mathrm{R}^{\mathrm{a}}$ & $95 \% \mathrm{Cl}$ & $\%$ & $O R^{a}$ & $95 \% \mathrm{Cl}$ \\
\hline \multicolumn{11}{|c|}{ Asthma in parents or siblings } \\
\hline No & 7418 & 2.5 & 1 & & 2.3 & 1 & & 1.9 & 1 & \\
\hline Yes & 1064 & 7.3 & 2.9 & $2.1-3.9$ & 7.6 & 2.9 & $2.3-3.7$ & 5.7 & 3.1 & $2.3-4.9$ \\
\hline \multicolumn{11}{|c|}{ Asthma as child or adolescent } \\
\hline No & 8287 & 2.4 & 1 & & 2.3 & 1 & & & . & . \\
\hline Yes & 195 & 30.8 & 22.2 & $15.2--32.4$ & 32.3 & 17.3 & $12.3-24.3$ & & . & . \\
\hline \multicolumn{11}{|l|}{ Production change } \\
\hline No & 8371 & 2.9 & 1 & & 2.8 & 1 & & 2.2 & 1 & - \\
\hline Yes & 111 & 21.6 & 8.4 & $4.5-14.3$ & 18.0 & 7.7 & $4.7-12.7$ & 13.5 & 6.2 & $3.4-11.2$ \\
\hline \multicolumn{11}{|l|}{ Animal production } \\
\hline No & 2043 & 2.5 & 1 & & 2.5 & 1 & & 2.3 & 1 & \\
\hline Yes & 6439 & 3.3 & 1.6 & $1.1-2.2$ & 3.1 & 1.4 & $1.05-1.8$ & 2.4 & 1.14 & $0.8-1.6$ \\
\hline \multicolumn{11}{|c|}{ Other dusty occupation } \\
\hline No & 6514 & 3.0 & 1 & . & 2.9 & 1 & & 2.2 & 1 & $\cdot$ \\
\hline Yes & 1968 & 3.6 & 1.2 & $0.9-1.6$ & 3.4 & 1.2 & $0.9-1.6$ & 2.9 & 1.3 & $0.9-1.8$ \\
\hline \multicolumn{11}{|l|}{ Smoking } \\
\hline Never & 4080 & 2.6 & 1 & . & 2.8 & 1 & & 2.1 & 1 & \\
\hline Ever & 4402 & 3.6 & 1.3 & $1.0-1.7$ & 3.2 & 1.2 & $0.9-1.5$ & 2.7 & 1.2 & $0.9-1.6$ \\
\hline \multicolumn{11}{|l|}{ Age (years) } \\
\hline $20-39$ & 1792 & 1.7 & 1 & . & 3.0 & 1 & . & 1.6 & 1 & \\
\hline $40-49$ & 2569 & 2.3 & 1.8 & $1.1-2.9$ & 3.9 & 1.7 & $1.2-2.3$ & 2.1 & 1.4 & $0.9-2.2$ \\
\hline $50-59$ & 2285 & 3.7 & 3.3 & $2.1-5.3$ & 5.1 & 2.3 & $1.3-3.1$ & 2.5 & 1.6 & $1.0-2.5$ \\
\hline $60-69$ & 1836 & 4.9 & 4.6 & $2.9-7.5$ & 7.0 & 3.1 & $2.0-4.2$ & 3.4 & 2.2 & $1.4-3.5$ \\
\hline \multicolumn{11}{|l|}{ Work status } \\
\hline Part-time farming & 2554 & 2.4 & 1 & & 3.9 & 1 & & 2.1 & 1 & \\
\hline Full-time farming & 5326 & 3.0 & 1.03 & $0.7-1.4$ & 4.5 & 1.1 & $0.8-1.4$ & 2.3 & 1.04 & $0.7-1.9$ \\
\hline Retired & 265 & 4.5 & 1.7 & $0.9-3.3$ & 5.7 & 1.4 & $0.8-2.5$ & 3.0 & 1.2 & $0.5-2.6$ \\
\hline Retired, health ${ }^{b}$ & 337 & 8.9 & 2.7 & $1.7-4.5$ & 11.9 & 2.6 & $1.7-3.9$ & 5.0 & 1.7 & $1.0-3.5$ \\
\hline Women & 2914 & 2.9 & 1 & . & 4.5 & 1 & . & 2.3 & 1 & . \\
\hline Men & 5568 & 3.2 & 1.0 & $0.8-1.4$ & 4.7 & 1.0 & $0.8-1.3$ & 2.4 & 1.0 & $0.7-1.3$ \\
\hline
\end{tabular}

a Odds ratios adjusted by all factors in the table in addition to gender.

b Retired for health reasons.

Retirement, change of production, age and gender

Change of production during the last 10 years because of dust nuisance was reported by 111 persons (table 5). Current asthma was reported by $21.6 \%$ of these persons (OR 9.6, 95\% CI 5.6-16.3). Retirement without a health reason was reported by 265 persons, and retirement for health reasons by 337 . The outcomes "asthma in adulthood" and "current asthma" showed significant associations with retirement for health reasons. Age was a significant risk factor for all 3 outcomes, with significant 
Table 6. Asthma indicators, heredity, and animal production among the smokers and never smokers $(\mathrm{N}=8482)$. (OR $=$ odds ratio, $95 \%$ $\mathrm{Cl}=95 \%$ confidence interval)

\begin{tabular}{|c|c|c|c|c|c|c|c|c|c|c|}
\hline \multirow[t]{2}{*}{ Smoking category } & \multirow[t]{2}{*}{ N } & \multicolumn{3}{|c|}{ Asthma now } & \multicolumn{3}{|c|}{ Asthma as adult } & \multicolumn{3}{|c|}{$\begin{array}{l}\text { Asthma started } \\
\text { in last } 10 \text { years }\end{array}$} \\
\hline & & $\%$ & $O R^{a}$ & $95 \% \mathrm{Cl}$ & $\%$ & $O R^{a}$ & $95 \% \mathrm{Cl}$ & $\%$ & $O R^{a}$ & $95 \% \mathrm{Cl}$ \\
\hline \multicolumn{11}{|l|}{ Never smokers } \\
\hline \multicolumn{11}{|c|}{ No asthma in parents or siblings } \\
\hline No animals & 890 & 1.2 & 1 & & 2.5 & 1 & & 1.5 & 1 & \\
\hline Animal production & 2694 & 2.3 & 2.16 & $1.12-4.15$ & 3.5 & 1.56 & $0.97-2.52$ & 1.8 & 1.29 & $0.69-2.4$ \\
\hline \multicolumn{11}{|c|}{ Asthma in parents or siblings } \\
\hline No animals & 88 & 2.3 & 1.91 & $0.41-8.87$ & 3.4 & 1.41 & $0.41-4.83$ & 1.1 & 0.77 & $0.10-6.00$ \\
\hline Animal production & 408 & 6.6 & 6.34 & $3.06-13.1$ & 10.5 & 5.01 & $2.92-8.60$ & 5.4 & 3.97 & $1.96-8.06$ \\
\hline \multicolumn{11}{|l|}{ Ever smokers } \\
\hline \multicolumn{11}{|c|}{ No asthma in parents or siblings } \\
\hline No animals & 945 & 2.6 & 1.85 & $0.90-3.83$ & 4.1 & 1.50 & $0.87-2.57$ & 2.3 & 1.45 & $0.72-2.91$ \\
\hline Animal production & 2889 & 3.0 & 2.54 & $1.34-4.84$ & 4.3 & 1.77 & $1.10-2.82$ & 2.0 & 1.40 & $0.76-2.58$ \\
\hline \multicolumn{11}{|c|}{ Asthma in parents or siblings } \\
\hline No animals & 120 & 10.8 & 8.54 & $3.67-20.2$ & 14.2 & 5.70 & $2.86-11.4$ & 8.3 & 5.24 & $2.20-12.5$ \\
\hline Animal production & 448 & 8.0 & 8.06 & $4.01-16.2$ & 11.6 & 5.65 & $3.35-9.54$ & 6.3 & 4.69 & $2.38-9.26$ \\
\hline
\end{tabular}

a Odds ratios adjusted for age, gender, work status, dusty occupation outside farming, and change in production.

odds ratios from the age of 50 years on and odds ratios of 2.4 to 2.8 for the highest age group of $60-69$ years. There were no associations with gender (OR 1).

\section{Combination of family history and exposure - evidence of interaction}

We also examined the effects of combinations of asthma among next-of-kin with the exposure factors animal production and smoking (table 6). The outcome "current asthma" for persons with no family history of athma showed an adjusted odds ratio of 2.16 (95\% CI 1.124.15) for animal production. The adjusted odds ratio was 1.91 (95\% CI 0.41-8.87) for family history for persons without animal production and 6.34 (95\% CI 3.06-13.1) for the combination of family history with animal production among never smokers. The relative excess risk for current asthma was calculated as 3.27 for the combination of animal production and family history of asthma among the never smokers. The relative excess risk was 3.04 for asthma in adulthood and 2.91 for asthma started in last 10 years for animal production in combination with family history among the never smokers.

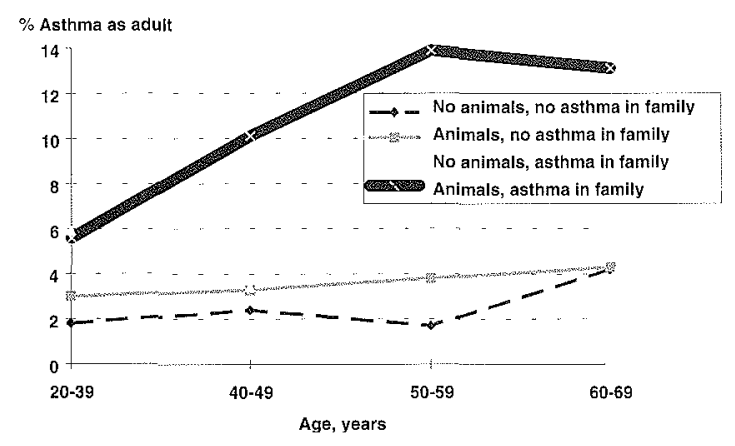

Figure 1. Family history of asthma, animal production, and age as risk factors for asthma as adult among never smokers $(N=4080)$.
The interactions between the factors smoking and family history of athma are shown in table 6 for persons with no animal production. For the outcome "current asthma", smoking gave an odds ratio of $1.85(95 \% \mathrm{CI}$ $0.90-3.83$ ) and for the combination with family history of athma the odds ratio was 8.54 (95\% CI 3.67-20.2), the relative excess risk being 5.78 for the combination of smoking and family history of asthma relative to these factors separately. In the same way the relative excess risk for asthma in adulthood was 3.79, and for asthma started in last 10 years it was 4.02 . For asthma in adulthood the relative excess risk for animals and family history of asthma was calculated to be 3.04, and for asthma started in last 10 years it was 2.91 .

Animal production and smoking combined demonstrated slightly higher odds ratios for the persons without a family history of asthma and equal or lower odds ratios for those with a family history.

The effects of the combination of family history and exposure in livestock production with age are illustrated in figure 1 for the never smokers. There was an increase in occurrence with age only in the group with livestock and a family history of athma.

To determine whether asthma among next-of-kin and the occurrence of asthma could be a result of common exposure on the farm, analyses of associations between "asthma ever" and "asthma in spouse" were performed, but no associations were found (OR $1.00,95 \%$ CI $0.58-$ 1.73). However, for current asthma and asthma in spouse the odds ratio was 1.49 (95\% CI $0.82-2.69)$.

The question "Did your asthma start for the first time during the last 10 years?" was difficult to validate crosssectionally. But only 8 persons reported both "asthma as a child or adolescent" and "asthma started (for the first time) during the last 10 years. Although the question 
identified cases of late onset of asthma, there were significant associations with asthma in the family (OR 3.2, 95\% CI 2.3-4.4) and with never smokers with dust exposure outside agriculture (OR 1.82, 1.03-3.15), which was more marked than with the other asthma-response categories.

\section{Discussion}

A family history of asthma and animal production were important single risk factors for asthma; less important were smoking and dusty occupations outside agriculture. Combinations of genetic predisposition, as indicated by family history and exposure factors, showed an enhanced risk relative to the factors separately in the additive interaction models.

Reliability in the sense of the 1-year repeatability of the information from the asthma questions in the questionnaire was evaluated for 280 respondents. The results for the different response categories can be classified as acceptable (asthma as an adult) to very good (asthma ever, cumulative asthma). The indicator of heredity, family history of asthma, showed a high 1-year repeatability.

Validity is a qualitative, conceptual issue that depends on the criteria for diagnosis and the methods of evaluation (15). Conceptual definitions of asthma as a syndrome with varying and, at least, partially reversible airway obstruction have gained international acceptance $(1,26,27)$. Bronchial hyperresponsiveness to various stimuli has been included in some definitions, but there are no good discriminating tests for asthma in epidemiology $(26,27-$ 29). The lack of a "gold standard" for identifying and classifying asthma makes it necessary to apply different operational definitions in epidemiologic studies $(1,2$, 13). Questionnaires have been developed for the detection of asthma and "asthma-like symptoms" in general populations (14, 16-18, 26-28, 30-33). Reporting of asthma on self-administered questionnaires may introduce random misclassification. Such an occurrence is less serious from an epidemiologic point of view than the systematic misclassification that can be introduced by other methods $(15,17,34)$.

Even with genes for asthma identified, there would be need for simple and cheap indicators of inheritance in epidemiology. Familial occurrence of asthma was observed in the 1920s (35), but it has been little studied in relation to occupational exposure, although atopy has been considered a genetic predisposition for asthma (3).

A family history of asthma showed high 1-year repeatability, but it is probably a very crude indicator of genetic predisposition. It may be affected by recall bias and common exposure in the farm environment.
However, the fact that there was no association between "asthma ever" among the farmers and their spouses (OR $1.00)$ does not indicate that common exposure on the farm and recall bias are important causes of the observed familial occurrence. However there was a weak, not significant association between current asthma and asthma in spouse (OR 1.49, 95\% CI 0.82-2.69) that may be exposure-related.

It can be hypothesized that a common childhood environment is a partial cause of familial associations. However, we have shown elsewhere that asthma in the offspring of farmers is not associated with animal production (36). Moreover, late onset asthma showed the same familial association as "asthma as child or adolescent".

Even for Mendelian traits the correlation between genes and phenotype in next-of-kin is never better than 0.5 (37) except for monozygotic twins. Therefore a family history of asthma underestimates the association between genotype and phenotype.

When genetic predisposition is not considered, the observed effects will be the results of a hypothesized hidden interaction between the effects of genetic factors and exposure (22). Table 6 indicates substantially lower effects of the exposures from animal production and smoking on persons without a family history than on those with a family history, and that there is an underlying interaction between exposure and genetic predisposition when analyzed according to the principles of additive interaction discussed by Rothman in 1986 (22), and recently by Hallqvist et al (24). However, the factors smoking and animal production combined seemed to obfuscate the effect of the other factor. Among the smokers there seemed to be a "healthy animal farmer effect" as a result of retirement and change of production to no animals in the group with a family history of asthma. This group had lower mean values for the standardized residuals of the $\mathrm{FEV}_{1,0}$ and more retirement and change of production than the others. [For smoking farmers who reported "asthma ever" with "family history of asthma" without current animal production the mean standardized residual of the $\mathrm{FEV}_{1.0}$ was $-1.00(95 \% \mathrm{CI}-0.155--0.445)$ and with animal production the mean standardized residual of the $\mathrm{FEV}_{1.0}$ was $-0.746(95 \% \mathrm{CI}-1.00-0.488)$, and from -0.242 to -0.377 for never smokers with asthma].

If one accepts "history of asthma among next-of-kin" as an, albeit crude, indicator of genetic predisposition, the present study supports the hypothesis of an interaction between genetic predisposition and exposure in animal production in the causation of asthma in farmers.

The chosen exposure indicator, animal production, represents daily exposure to antigens, allergens, particles from animals, and microorganisms in fodder and bedding materials $(4,6,38,39)$. The relevance of the many 
different exposure factors for airway disease are not known (7). Indicators of selection (retirement and change of production) showed an association with asthma, but there was no definite pattern for change in production.

Smoking did not seem to be an important risk factor for asthma when studied in the whole population, as shown in table 5 , but it diluted the effect on associations with the other exposure factor, animal production. That smoking is a weak determinant for asthma (when inheritance is not considered) is in accordance with a longitudinal study of asthma in a general population (40). However, when analyzed for persons without animal production and in combination with heredity, the association with smoking was highly significant and showed the same pattern of interaction as animal production (table 6). This finding seems to indicate that smoking is particularly harmful to predisposed persons, and it is confirmed by the lung function data, which showed lower standardized residuals for the $\mathrm{FEV}_{1.0}$ of the asthmatic smokers. It is probable that smoking asthmatics more often become severely affected or chronically obstructed than nonsmokers.

In a general population study in Hordaland, Norway $(\mathrm{N}=4992), 46 \%$ of the men had ever been exposed to dust or gases in their work (18). We found that $32-42 \%$ of the male farmers had ever had dusty occupations outside farming, and for the lowest exposed group, "never smokers with no livestock and no dust outside farming" the prevalence of current asthma was $1.1 \%$. The cumulative prevalence of "physician diagnosed asthma" was $2.1 \%$ in comparison with $2.4 \%$ for the lowest exposed (or "unexposed") group in the Hordaland study. This finding seems to indicate that the farmers without animal production were comparable to the lowest exposed sector of the general population and that one should be cautious when using general populations as "unexposed" external references in cross-sectional studies, as pointed out by Checkoway et al (41).

\section{Concluding remarks}

Important determinants for asthma in this population of farmers were a family history of asthma, asthma in childhood or adolescence, animal production, age or years in agriculture, and smoking. For asthma with a late onset ("started last 10 years") among the never smokers, even dust exposure outside agriculture was significant. Combinations of exposures gave higher risks than single exposures.

"Asthma among next-of-kin" was studied as a crude indicator of genetic predisposition and showed interactions with the exposure factors animal production and smoking in additive interaction models. The necessity of considering indicators of both inheritance and exposure is emphasized.

\section{References}

1. Burr M, L. Epidemiology of asthma. In: Burr ML, editor. Epidemiology of clinical allergy. Basel: Karger, 1993:80102. Monogr Allergy.

2. Gregg I. Epidemiological aspects. In: Gregg I, Clark TH, Godfrey S, editors. Asthma. 2nd ed. London: Chapman and Hall Medical, 1983:242-84.

3. Sandford A, Weir T, Pare P. The genetics of asthma. Am $\mathbf{J}$ Respir Crit Care Med 1996;153:1749—65.

4. Donham KJ. Hazardous agents in agricultural dusts and methods of evaluation. Am J Ind Med 1986;10(3):205-20.

5. Rylander R. Organic dusts and lung disease: the role of inflammation. Ann Agric Environ Med 1994;1(1):7-10.

6. Kotimaa MH, Oksanen L, Koskela P. Feeding and bedding materials as sources of microbial exposure on dairy farms. Scand J Work Environ Health 1991;17:117-22.

7. Donham KJ, Thorne PS. Agents in organic dust: criteria for a causal relationship. Am J Ind Med 1994;25:33-9.9.

8. Iversen M, Pedersen B. Relation between respiratory symptoms, type of farming, and lung function disorders in farmers. Thorax 1990;45:919-23.

9. Rylander R. Lung diseases caused by organic dusts in the farm environment. Am J Ind Med 1986;10(3):221-7.

10. Terho EO. Work-related respiratory disorders among Finnish farmers. Am J Ind Med 1990;18(3):269-72.

11. Choudat D, Goehen M, Korobaeff M, Boulet A, Dewitte JD, Martin MH. Respiratory symptoms and bronchial reactivity among pig and dairy farmers. Scand J Work Environ Health 1994;20:48-54.

12. Van Hage-Hamsten M, Johansson S, G, Høglund S, Tull P, Wiren A, Zetterstrøm O. Storage mite allergy is common in a farming population. Clin Allergy 1985;15:555-64.

13. Burney P, Detels R, Higgins M, Peckham C, Samet JM, Tager I. Recommendations for research in the epidemiology of asthma. Chest 1987;91S:S194-5.

14. Lundbaeck B, Stjernberg N, Rosenhall L, Lindstrøm M, Jønsson $\mathrm{E}$, Andersson S. Metacholine reactivity and asthma: report from the Northern Sweden obstructive lung disease project. Allergy 1993;48:117-24.

15. Thoren K, Brisman J, Jarvholm B. Asthma and asthma-like symptoms in adults assessed by questionnaires. Chest 1993;104:600-8.

16. Venables KM, Farrer N, Sharp L, Graneek BJ, Newman Taylor A. Respiratory symptoms questionnaire for asthma epidemiology: validity and reproducibility. Thorax 1993;48:2149.

17. Gulsvik, A. Obstructive lung disease in an urban population [dissertation]. Oslo: Department of Lung Diseases, The National Hospital, University of Oslo, 1979.

18. Bakke P, Eide GE, Hanoa R, Gulsvik A. Occupational dust or gas exposure and prevalences of respiratory symptoms and asthma in a general population. Eur Respir J 1991;4:273-8.

19. American Thoracic Society, Gardner RM, Hankinson JL, Crapo RO, Johnson RL, Epler GR. Standardization of spirometry - 1987 update. Am Rev Respir Dis 1987;136:1285—98.

20. Cotes JE. Lung function. Oxford: Blackwell Scientific Publications, 1986:18-20. 
21. Cohen J. A coefficient of agreement for nominal scales. Educ Psychol Meas 1960;20(1):37-46.

22. Rothman KJ. Modern epidemiology. Boston (MA): Little, Brown, \& Co, 1989:299-304, 311-26.

23. Hosmer DW, Lemeshow S. Applied logistic regression. New York (NY): John Wiley \& Sons, 1989:82-144.

24. Hallqvist J, Ahlbom A, Diderichsen F, Reuterwall C. How to evaluate interaction between causes: a review of practices in cardiovascular epidemiology. J Int Med 1996;239:377-82.

25. Melbostad E, Wijnand E, Magnus P. Chronic bronchitis in farmers. Scand J Work Environ Health 1997;23(4):271-80.

26. American Thoracic Society. Chronic bronchitis, asthma and pulmonary emphysema: a statement by the committee of diagnostic standards for nontuberculous respiratory diseases. Am Rev Respir Dis 1962;85:762—9.

27. O'Connor GT, Weiss ST. Clinical and symptom measures. Am J Respir Crit Care Med 1994;149:S21—8.

28. Burr ML. Diagnosing asthma by questionnaire in epidemiological surveys. Clin Exp Allergy 1992;22:509-10.

29. Samet JM. A historical and epidemiologic perspective on respiratory symptom questionnaires. Am J Epidemiol 1978;108(6):435- 46.

30. Dales RE, Ernst P, Hanley JA, Battista RN, Becklake M. Prediction of airway reactivity from response to a standardized respiratory symptom questionnaire. Am Rev Respir Dis 1987;135:817-21.

31. Enarson D, Vedal S, Schultzer M, Dubyncio A, Chan-Yeung M. Asthma, asthmalike symptoms, chronic bronchitis an the degree of bronchial hyperresponsiveness in epidemiologic surveys. Am Rev Respir Dis 1987;136:613-7.

32. Samet J. Epidemiologic approaches for the identification of asthma. Chest 1987;91 suppl 6:74s-8s.

33. Burney PG, Laitinen LA, Pedrizet $S$, Huckauf H, Tattersfield
$\mathrm{AE}$, Chinn $\mathrm{S}$, et al. Validity and repeatability of the IUATLD (1984) bronchial symptoms questionnaire: an international comparison. Eur Respir J 1989;2:940 — 5.

34. Dodge R, Cline MG, Burrows B. Comparisons of asthma, emphysema and chronic bronchitis diagnoses in a general population sample. Am Rev Respir Dis 1986;133:981—6.

35. Rackemann FM. Studies in asthma: a clinical survey of 1074 patients with asthma followed for two years. J Lab Clin Med $1927 ; 12: 1185$-97.

36. Melbostad E, Eduard W, Magnus P. Asthma in the offspring of farmers: the importance of asthma and atopy in parents and environmental factors [abstract]. Eur Respir J 1997;25 suppl $10: 142 \mathrm{~s}$.

37. Stucker I, Hemon D, Bonaiti-Pellie C. Epidemiology of lung cancer: interaction between genetic susceptibility and environmental risk factors. In: Hirsch A, Goldberg M, Martin J, Masse R, editors. Prevention of respiratory diseases. New York (NY): Marcel Dekker Inc, 1993:149-65.

38. Donham K, Haglind P, Peterson Y, Rylander R, Belin L Environmental and health studies of farm workers in Swedish swine confinement buildings. Br J Ind Med 1989;46:31-7.

39. Virtanen TI, Mäntyjärvi RA. Airborne allergens and their quantification and effect on the development of allergy in occupational environments. Appl Occup Hyg 1994;9(1):6570.

40. Vesterinen E, Kaprio J, Koskenvuo M. Prospective study of asthma in relation to smoking habits among 14729 adults. Thorax 1988;43:534-9.

41. Checkoway H, Pearce N, Crawford-Brown DJ. Research methods in occupational epidemiology. New York, Oxford: Oxford University Press, 1989:215.

Received for publication: 28 July 1998 